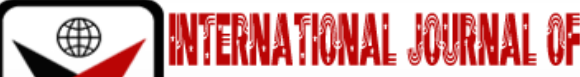

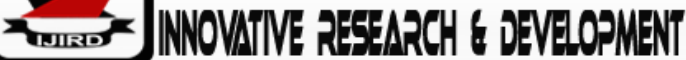

ISSN 2278-0211 (Online)

\section{Management Information System (MIS): The Importance and Benefits of Marketing Intelligence to Support Nigerian SMEs Decision Making}

\author{
Abdulkadir, Ahmed Surayyah \\ Lecturer, Department of Marketing, Baze University Abuja, Nigeria
}

\begin{abstract}
:
The study examines how important it is for Nigerian SMEs to have access and use marketing intelligence and its effect as a competitive advantage. Online survey was conducted for the safety of to the researcher and respondents due to the covid-19 pandemic. 110 selected SMEs were chosen for the study using convenient sampling. Questionnaire was used in collecting data. The statistical tool for data analysis was regression. The findings revealed that there is a weak link between marketing intelligence and SMEs decision making. Recommends of the points out that government agencies should support SMEs by providing them with technologies that can operate marketing intelligence, also recommended further researchers should work with larger set of respondents and variables to add to the little literature on marketing intelligence and decision making.
\end{abstract}

Keywords: Marketing intelligence, SMEs, decision making

\section{Introduction}

Small and Medium Scale Enterprises (SMEs) have played important roles in the development process in most economies, and have proved to be one of the most viable sectors with economic growth potentials, (Gonzalez 2003). According to the Nigeria Bureau of Statistics, SMEs in Nigeria have contributed about forty-eight percent (48\%) of the national GDP in the last five (5) years. With a total number of about 17.4 million, they account for about fifty percent $(50 \%)$ of industrial jobs and nearly ninety percent $(90 \%)$ of the manufacturing sector, in terms of number of enterprises. SMEs constitute $97.2 \%$ of the companies in Nigeria and on average, fifty percent (50\%) of Nigeria's employment and fifty percent (50\%) of its industrial output (General Statistics Office, 2007). They also contribute to national development by positively influencing the distribution of income in both functional and nominal terms (Uzor, 0.0. 2004), they achieve more relatively high value-added operations because they are propelled by basic economic activities that depend mostly on locally sourced raw materials, they provide opportunities for the development of local skills acquisition through adaptation (Rogers, B.A. 2002)

However, the SMEs sector has not been able to perform the expected vital and vibrant role in bringing about economic growth and development of the country. Unemployment is endemic (Osalor, 2010 www.sudesca.org) because the SMEs are confronted with few drawbacks and challenges, they have to overcome in order to operate successfully. These challenges have hindered SMEs from employing as much as they should, the SMEs are unable to generate wealth as they should and their contribution to poverty reduction is also hindered. One of the factors affecting the performance of SMEs is effective decision making (Ndayako 2015).

Marketing intelligence provides companies with information that allows sound decision making (Gilad, 1991). MI recognizes that the marketing environment is constantly changing and presenting new opportunities and threats, which can be detected, collected, analyzed and utilized. An organization should understand the importance of continuously monitoring and adapting to their environment. Marketing intelligence is highly recommended in industries since the quality of the marketing information affect the effectiveness of decision making Irrespective of the sector of the economy or market an organization operates (Goddy Osa 2014). For companies to maximize opportunity they must assess their strategic position only then will executives be able to decide where and how the company should position itself. Evaluations of past marketing performance, strengths and weaknesses, quality of products, utilization issues need to be addressed. Strategic planning and marketing intelligence is the best way to handle these issues (Jaworski and Wee, 1993).

\subsection{Statement of the Problem}

Goddy's research aimed at finding the impact of marketing intelligence systems on decision making. This research aims to cover the gap between Goddy (2014) impact of marketing intelligence system on decision making and impact of marketing intelligence system on decision making in Nigerian SMEs. 


\subsection{Research Questions}

- What is the Impact of marketing Intelligence in Nigerian SMEs decision making?

- What is the effect of using marketing intelligence as a competitive edge for Nigerian SMEs?

\subsection{Research Objectives}

It aims to examine how important it is for SMEs to have access and use marketing intelligence and its effect as a competitive advantage.

\subsection{Statement of Hypothesis}

- Ho1: Marketing intelligence has no impact on Nigerian SMEs decision making

- Ho2: Using marketing intelligence has no effect as a competitive edge for Nigerian SMEs

\subsection{Significance of Research}

This study will provide a better understanding of Marketing Intelligence to marketing managers and SMEs in making sound decisions. it will obtain competitive advantage that will benefit Nigerian SMEs to grow, this will help in the effective production and promotion of 'made in Nigeria' goods. It hopes to guide SMEs and marketing managers strategize the way they handle data, factors and information and understand how they can process information in a more rapidly, greater accuracy than ever before. Mangers will be able to forecast as well as control their marketing activities. The study will aid SMEs arrange, visualize market intelligence and detect market opportunities. It will Increase the research knowledge on Market Intelligence and how to use it in Nigeria by providing an alternative to marketing researchers. but it does not mean that marketing intelligence has no impact on SMEs decision making or using marketing intelligence does not have an effect as a competitive advantage.

\section{Literature Review}

\subsection{Small Medium Enterprises (SMEs) in Nigeria}

There are many definitions of SMEs, some scholars and organizations have defined it as the following:

- Nwokoye (1988) referred to SMEs as businesses employing between five and one hundred workers with an annual turnover of about four hundred thousand Naira (N400, 000).

- The Federal Ministry of Commerce and Industry referred to SMEs as enterprises with a total investment, excluding cost of land but including capital of up to seven hundred and fifty thousand (N750,000) with a paid employment up to fifty (50) people.

- Small and Medium Industries Equity Investment Scheme (SMIEIS) defined it as those companies that has a total capital employed above one million five hundred thousand but not surpassing two hundred million including working capital and excluding cost of land, with ten (10) employees but not above three hundred (SMIEIS 2006)

- Small Medium Enterprises Development Agency of Nigeria (SMEDAN) defines SMEs on the following criteria: small scale companies are businesses with ten (10) to forty-nine (49) people with an annual turnover of five to forty-nine million Naira while a medium scale companies that have fifty (50) to one hundred and ninetynine (199) employees with a year turnover of fifty to four hundred and ninety-nine million Naira (SMEDAN 2005)

\subsection{Marketing Intelligence (MI)}

Marketing intelligence system is a procedure or data used by managers to acquire their everyday information about pertinent developments in the marketing environment (Kotler and Armstrong, 1997). These information about the development in the environment are shared to the managers to be used as a basis for marketing decision. (Goddy 2014) According to Caudron (1994, p. 39), market intelligence serves four primary purposes. These are:

- Competitors' assessment and tracking.

- Early warnings of opportunities and threats.

- Support for strategic planning and implementation.

- Support of strategic decision-making.

The benefits of marketing intelligence according to (Goddy 2014):

- Decision making: Marketing intelligence is an important tool and technique in gathering relevant information for the executives in making decision under certainty, uncertainty and risk. It provides marketing managers with a decision support system.

- Speed and Accuracy: It provides information faster; it is less expensive and It provides more complete information for organizational uses.

- Big Data: Marketing intelligence storage and retrieval capacity allows a variety of data to be collected and utilized.

- Strategic Management: It helps marketers to monitor the performance of the products, sales people and other marketing units in greater details and if there is any deviation, the concerned party will be aware. It helps in market segmentation, it is an effective tool in both price and non-price competition. 


\subsection{Empirical Review and Analysis of Related Work}

Goddy's (2014) research aimed at finding the relationship and impact of marketing intelligence systems on decision making. the research paper concluded that, there are many factors that have increased the need for more and better information as organizations become local and globalized, they require vast information, need better information on the effectiveness of their marketing strategic tools because in today's rapidly changing environment managers need up-todate information to make timely decision. The cited case studies he used for the research were conducted years ago, especially in foreign countries, which might be affected by changes. This means that he used secondary data as his source of information. This particular problem leads to the question of whether the finding and theories are outdated or not, especially in Nigeria.

Nevertheless, it is fair to apply his theories to all categories of organizations, Startups, SMEs and large scale businesses in order to attain more accurate information regarding his research and market intelligence by using primary data as a source of information. He recommended for further empirical studies, the researcher could make use of a larger sample size and employ questionnaires interview method of collecting the data in order to have capture a broader view of the respondents and to take care of those lapses, that might have resulted from the single use of a questionnaire.

\subsection{Theoretical Framework}

Marketing Research: Zikmund (1996, p. 4) defined marketing research as the principal tools for linking the target customers and the public to the market through information used to identify marketing performance and improves understanding of marketing as a process. This study aims to promote enough information, which will help the marketing manager to make intelligent decisions. (Goddy 2014). There are two methods of conducting a market research and they are qualitative and quantitative research approaches. (Aaker et al., 1995, p. 778; Zikmund, 1996, p. 192).

Marketing Information System: Marketing information system is developed from marketing intelligence, marketing research system and marketing decision support analysis (Kottler, 2003). It is referred to a structured, interacting complex of people, machines and procedures designed to generate an orderly flow of pertinent information collected from both intra and extra-companies' environment for use as the bases for decision making in particular areas of marketing management (Brien 1997). The definition implies that the independent activity is associated with the collection of marketing information, both from internal and external environment. The information is collected to facilitate decision making in different areas of marketing management (Adeoti. J. O, Olawale.Y. A, Abolarinwa. O. 0, 2016).

Marketing Decision Support System (MDSS):Marketing Decision Support System is aimed at aiding and improving marketing decision making, it is also aimed at the complex, less-structured problems encountered within the marketing domain (Cassie 1997). MDSSs can be categorized according to questions. It has a functionality level 1 , when it can answer questions like "What happened". These can provide information about customers, sales, competitors, etc. MDSS has a functionality level 2, when it can answer questions like "Why did it happen". These can analyze the effects of own and competitors' marketing actions. They analyze causes of changes in the market. MDSS has a functionality level 3, when it can answer questions like "What will happen if". These can forecast the effect of marketing actions by using mathematical models to compute the outcome of different actions. MDSS has a functionality level 4, when it can answer questions like "What should happen". These intend to find the best marketing strategy in a given situation (Wierenga. B, Ophuis. P, Huizingh. E, Campen. P., 1994).

Marketing Intelligence: In addition to the literature review provided above, Marketing intelligence as a strategic tool for competitive edge, Goddy's (2014) research paper explores the effect of marketing intelligence in businesses. It is needed in Nigeria because of a) Uncertainty of Future Events i.e., to organize information in such a way that it will aid the managers in forecasting as well as in controlling current marketing activities. b) Complexity of Some Marketing Activities i.e.,the need for a company to survive demands for the business to be monitored, Information to be collected as well as analyzed to know the strength, weakness, opportunities and threats of both its competitors and its environment. c) Low Quality Made - In Nigeria Goods i.e., consumers are dissatisfied with made-in - Nigeria goods. Adequate information is necessary so quality of products to be produced is improved. d)Shortage of Raw Material i.e., companies need to search for pertinent information that can assist them in making the best use of the available raw material. e) Information Processing Technology, with advanced information processing technologies, more information can now be processed more rapidly, with greater accuracy and accessibilities than ever before.

\section{Research Method}

The primary focus of this research is to determine the Impact of MI on Nigerian SMEs' decision making and the effect of using marketing intelligence as a competitive edge for Nigerian SMEs. Goddy (2014) suggested for further studies, the researcher should use a larger sample size and employ questionnaires method of collecting the data in order to capture broader views of the respondents. Online survey was conducted due to the covid-19 pandemic for the safety of the researcher and respondents. The Questionnaire method was used in collecting the data. The questions were structured to focus on Caudron (1994) primary purposes of market intelligence and questions related to the impact of MI in Nigeria SMEs' decision making. Likert rating scale of five points which range from strongly agreed to strongly disagree was constructed to enable the respondents to give their opinions to items in the questionnaire. Convenient sampling method was used to select the participants of the study, which were 110 SMEs managers and marketing managers since they are the coordinators of their business / Marketing activities, respectively. The SMEs selected for this study are businesses registered with SMEDAN within Abuja metropolis, the Capital of Nigeria. Regression analysis will be used as a statistical tool to test the hypotheses formulated

for the study. 


\section{Findings}

\begin{tabular}{|c|c|}
\hline Responses & Percentages \\
\hline Small & $62.5 \%$ \\
\hline Medium & $37.5 \%$ \\
\hline
\end{tabular}

Table 1: Scale of Business

Table 1 shows $62.5 \%$ of respondents work with small scale businesses meaning more than half of the respondents while $37.5 \%$ work with medium scale businesses.

\begin{tabular}{|c|c|}
\hline Responses & Percentages \\
\hline Beauty/Fashion & $35 \%$ \\
\hline Retail / Wholesale & $17.5 \%$ \\
\hline Food & $22.5 \%$ \\
\hline Health & $2.5 \%$ \\
\hline Consultancy & $7.5 \%$ \\
\hline Other & $15 \%$ \\
\hline Table 2: Categories of Industry of the Respondents
\end{tabular}

Table 2 shows the respondents' work sector.35\% of managers who participated are in beauty/fashion.17.5\% of managers who participated are in retail/wholesale. $22.5 \%$ of managers who participated are in the food industry. $2.5 \%$ of managers who participated are in health services, $7.5 \%$ of managers who participated are in consultancy. $15 \%$ of managers who participated in other sectors.

\begin{tabular}{|c|c|c|c|c|}
\hline Model & R & R square & Adjusted R Square & Std. Error of the Estimate \\
\hline 1 & 0.227 & 0.051 & 0.006 & 1.282 \\
\hline
\end{tabular}

Table 3: Model Summary of the Simple Regression for Effect on New Entrants

Table 3 indicates R Square equals 0.051 means that $5.1 \%$ of the variabilities of SMEs decision making is explained by Marketing Intelligence. Correlation (R) equals 0.227 means that there is a weak direct relationship between Marketing Intelligence and SMEs decision making.

\begin{tabular}{|c|c|c|c|}
\hline Model & df & F & p-value \\
\hline Regression & 5 & 1.128 & 0.35 \\
\hline
\end{tabular}

Table 4: ANOVA

- Ho1: Marketing intelligence has no impact on Nigerian SMEs decision making

While Table 4 p-value $=0.35$ and since p-value $<<$ a $(0.05)$, we can reject the null hypothesis 'Ho1: Marketing intelligence has no impact on Nigerian SMEs decision making' and accept that marketing intelligence has an impact on Nigerian SMEs decision making.

\begin{tabular}{|c|c|c|c|c|}
\hline Model & R & R square & Adjusted R Square & Std. Error of the Estimate \\
\hline 1 & 0.215 & 0.046 & 0.037 & 1.354 \\
\hline
\end{tabular}

Table 5: Model summary of the simple regression for effect on new entrants

Table 5 indicates R Square equals 0.046 means that $4.6 \%$ of the variability of Competitive advantage is explained by Marketing Intelligence. Correlation (R) equals 0.215 means that there is a weak direct relationship between marketing intelligence and competitive advantage

\begin{tabular}{|c|c|c|c|}
\hline Model & df & F & p-value \\
\hline Regression & 1 & 5.25 & 0.024 \\
\hline
\end{tabular}

Table 6: ANOVA

- Ho2: Using marketing intelligence has no effect as a competitive advantage for Nigerian SMEs

Tables 6 shows that $\mathrm{p}$-value $=0.024$ and since $\mathrm{p}$-value $<\mathrm{a}(0.05)$, we have to reject the null hypothesis 'Ho2: Using marketing intelligence has no effect as a competitive advantage for Nigerian SMEs' and accept that using marketing intelligence has an effect as a competitive advantage for Nigerian SMEs.

The results indicate that there is a weak, direct relationship between marketing intelligence and SMEs decision making and competitive advantage but it does not mean that marketing intelligence has no impact on SMEs decision making or using marketing intelligence does not have an effect as a competitive advantage. This study is in line with Goddy (2014) who found that there is a relationship and impact of marketing intelligence systems on decision making using case studies from different countries except Nigeria. Which mean his finding are not outdated. 


\section{Conclusion}

The study concluded that marketing intelligence in Nigerian SMEs decision making is important for competitive edge and SMEs should invest in software or systems to help them track down fast environmental information that can help with their marketing activities, boost sales and get ahead of competitors. The study recommends that investors and government agencies should support SMEs by providing them with the best technologies that can operate marketing intelligence. It is also recommended that further researchers should work with larger set of respondents and variables to add the literature on marketing intelligence and decision making.

\section{References}

i. $\quad$ Aaker, D.A., Kumar, V. and Day, G.S. (1995). Marketing Research, John Wiley and Sons, Inc., New York, NY.

ii. Adeoti. J, Olawale. Y, Abolarinwa. O. (2016) Impact of Marketing Information System on Product Performance in Nigerian Bottling Company Limited. KIU Journal of Social Sciences Kampala International. University ISSN: 1996902-3; 2(2): 221-236

iii. B. Wierenga, P. Ophuis, E. Huizingh, P. Campen, Hierarchical scaling of marketing decision support systems, Decision Support Systems 12 (3) (1994) 219 - 232.

iv. Beri, G.C. (2007) Marketing Research: Research Design, 4thEdition, London: McGraw-Hill, Tata Education Pvt. Ltd

v. Cartwright, D.L., Boughton, P.D. and Miller, S.W. (1995), "Competitive intelligence system: relationships strategic orientation and perceived usefulness", Journal of Managerial Issues, Vol. 7 No. 4, pp. 420-34.

vi. Caudron, S. (1994), "I spy, you spy", Industry Week, 10 March, pp. 35-40. General Statistics Office. (2007). Small and Medium Enterprises in Nigeria. International Journal of Academic Research in Business and Social Sciences March 2015, Vol. 5, No. 3 ISSN: 2222-6990

vii. Kotler, P. and Armstrong, G. (1997), Principle of Marketing, Prentice Hall International, Englewood Cliffs, NJ.

viii. Kotler P. (2003): Principles of Marketing 6 $6^{\text {th }}$ Edition, New Delhi, Prentice Hall of India Private Limited.

ix. Little D.C. (1998), 'Brandand' A Marketing Mix Model Part 1, Structure Part II. Implementation, Operation Research, January.

x. $\quad$ Malhotra, N. (1996), Marketing Research, An Applied Orientation, Prentice Hall, NJ.

xi. Mohammed S. A, Aminu. A, Rahama L. A, Kamalu. U, et al., 2015. The Nature of Small and Medium Scale Enterprises (SMEs): Government and Financial Institutions Support in Nigeria

xii. Mohammed, U. D., \& Obeleagu-Nzelibe, C. G. (2014). Entrepreneurial Skills and Profitability of Small and Medium Enterprises (SMEs): Resource Acquisition Strategies for New Ventures in Nigeria. Proceedings of 25th International Business Research Conference 13 -14 January, 2014, Taj Hotel, Cape Town, South Africa

xiii. Nwokoye, N. G. (1988). 'Marketing Strategies for Small Business under SAP'. Business Concord. Lagos. May 13th.

xiv. Rogers, B.A. (2002). Funding of SMEs: Sourcing of Funds and Problems Limiting Access, ICAN journal. Nigerian Accountant Vol. 35 No. 1 January/March.

xv. Small and Medium Industries Equity Investment Scheme (SMIEIS) (2006). A paper Presented at the National Summit on SMIEIS Organized by the Bankers" Committee and Lagos Chambers of Commerce and Industry (LCCI), Lagos on 10th June 2003. Retrieved on 15/06/2008 from http://www.cenbank.org/OUT/SPEECHES/2003/GOVADD-10BJUNE.PDF

xvi. SMEDAN. (2005). Small and medium enterprises performance in Nigeria: A report presented at African entrepreneurship seminar organized in collaboration with the Scientific Committee on Entrepreneurship of the University of Essex. United Kingdom on the 5th of June.

xvii. Uzor, 0.0. (2004). Small and Medium Scale Enterprises Cluster Development in South Eastern Region of Nigeria. Institute for World Economics and International Management, 5-15.

xviii. Z Zikmund, W.G. (1996), Exploring Marketing Research, The Dryden Press, Fort Worth, TX 